\title{
Exploring the Effectiveness of Communication Strategies Through Pro-Active Listening in ELF-Informed Pedagogy
}

\author{
Blagoja Dimoski \\ Tamagawa University, Tokyo, Japan \\ Yuri Jody Yujobo \\ Tamagawa University, Tokyo, Japan \\ Mitsuko Imai \\ Tamagawa University, Tokyo, Japan
}

\begin{abstract}
This study explores the effectiveness of communication strategies (CSs) through pro-active listening (PAL) comprehension activities for students to actively negotiate and co-construct meaning in an English as a lingua franca (ELF)informed pedagogy. Data was collected from fifty-three Japanese students in classes at the Center for English as a Lingua Franca (CELF) at Tamagawa University. Quantitative and qualitative methods were employed. Responses to a pre- and post- questionnaire on the perceived effectiveness of CS use, transcribed speech collected during PAL comprehension activities, and written reflections by students were analyzed. The findings suggest that an ELFinformed pedagogy of explicit teaching of CSs increases students' perceived ability to use CSs effectively in PAL activities. ELF pedagogy should incorporate opportunities for students to explicitly learn and use CSs independently to become competent international communicators among other ELF speakers.
\end{abstract}

The number of non-native users of English worldwide vastly exceeds that of native speakers (Graddol, 2003). This discrepancy is expected to grow, resulting in 1.2 billion non-native users (p. 163) and 433 million native speakers (p. 156) by 2050. Given this context, it is important for educators to realize that their non-native English speaking (NNES) students may find themselves in various work or social situations requiring communication with people from other countries who are not native speakers of English. English language educators should steer their approach in the direction of English as a lingua franca (ELF), defined by Seidlhofer (2011) as the "use of English among speakers of different first languages for whom English is the communicative medium of choice, and often the only option" (p. 7).

Tamagawa University's Center for English as a Lingua Franca (CELF), the first such center in Japan, designed its program to promote an ELF setting, as it recognizes the potential future need

Language Education in Asia, 2016, 72), 67-87. https://doi.org/10.5746/LEiA/16/V7/I2/A02/Dimoski_Yujobo_Imai 
for students to use ELF and interact with a variety of English users. The CELF also employs NNES teachers with multilingual and multicultural backgrounds to promote an ELF setting. CELF Program students have rich opportunities to interact with these teachers in formal classroom settings and informal one-on-one tutoring sessions. The CELF's goal for ELF proficiency of students is not to reach native English norms, but rather, to achieve "competence in a repertoire of English varieties" (Canagarajah, 2006, p. 229). The CELF finds ELF-informed pedagogy a preferred method to develop an ELF-oriented curriculum which involves raising an awareness of the use of language and the negotiation and accommodation of linguistic form and meaning. This may include, according to ELF researchers (Björkman, 2014; Kaur, 2014; Wen, 2012), incorporating communication strategies (CSs).

Few formal studies have been done on ELF pedagogy. Choi and Jeon (2016) claimed that thus far, "ELF pedagogy has been mostly discussed at only a conceptual level and pedagogical research is scarce" (p. 1). Therefore, the authors were motivated to research the effectiveness of explicit teaching of CSs through pro-active listening (PAL) comprehension activities. Data was collected by a questionnaire administered pre- and post-CS training, analysis of transcribed dialogic speech, and written student reflections to determine the effect explicit teaching of CSs through PAL activities had on student perceptions of improvement in their communication skills. This paper consists of five main parts: the literature review and research questions, methodology, major findings, discussion, and conclusion.

\section{ELF and CSs}

\section{Literature Review}

Seidlhofer (2011) claimed that in ELF interactions, the primary focus is on communicative efficiency and what people actually do with the language they have learned. Of importance is how one communicates in English as an additional language, rather than setting native speaker competence as the target, and analyzes ELF interactions of high functional load around, for instance, pronunciation, through various strategies and processes to achieve mutual understanding to co-construct meaning. One of the ways to co-construct meaning is through the use of CSs. Examples of CSs discussed in ELF literature include, but are not limited to, accommodation, repetition, nonverbal strategies, hypothesis forming (Cogo \& Dewey, 2012), seeking clarification, checking for understanding, paraphrasing, and being explicit (Kaur, 2014).

Although there is much alignment between CSs in ELF and non-ELF interactions, achievement or compensatory strategies (e.g., using circumlocution, approximation, or gestures) are more prevalent in ELF settings (Björkman, 2014). Björkman, who categorized CSs into self-initiated and other-initiated types, found that in ELF settings, the most frequently occurring self-initiated CSs were explicitness strategies and comprehension checks, while in other-initiated CSs, confirmation checks and clarification requests were the most common. This suggests "speakers in ELF settings do pro-active work for communicative effectiveness" (p. 129).

However, discussion of CSs in the literature has focused, in large part, on ELF users (see Björkman, 2014; Burch, 2014; Cogo \& Dewey, 2012; Kaur, 2016; Mauranen, 2012). In contrast, the focus of the current study is ELF learners preparing for real-world ELF contexts.

\section{ELF-Informed Pedagogical Framework}

The authors used Wen's (2012) pedagogical framework for an ELF-informed approach which emphasizes that learners should not replicate what was taught, but rather "use it as a means for developing effective communication strategies related to their own cultural reality" (p. 373). The framework is unique in that it encompasses views about both language and teaching on 
three levels. Language is viewed in terms of its (a) linguistic, (b) cultural, and (c) pragmatic functions, which correspond to the pedagogical goals of (a) effective communication skills, (b) intercultural competence, and (c) abilities to generate appropriate communicative rules and strategies.

Although a thorough implementation of Wen's (2012) shift in pedagogic orientation was beyond the scope of this study, aspects of the framework were realized to some degree. Following Wen's recommendations regarding the linguistic component of the framework, warm-up lesson material was developed with the aim of (a) exposing students to language and subject matter which is relevant to their own life experiences from a cultural perspective and (b) prioritizing effective communication skills over native-like performance. Wen also stated that, phonologically, students should be "able to produce comprehensible English and understand English with non-native accents" (p. 374). Concerning cultural objectives, the warm-up questions, the main lesson content, and the follow-up discussion questions provided opportunities for students to reflect on three types of cultures: "target language cultures, the cultures of other non-native speakers, and the learner's own culture" (p. 374). Regarding pragmatics, students were explicitly taught CSs to develop strategic competence.

PAL comprehension. PAL comprehension is an approach that transforms traditional forms of listening comprehension (LC) activities, in which students are passive receptors of auditory input, into dialogic events more reflective of real-world processes. PAL does this by adding another layer to standard LC activities to make the source of auditory input accessible to students (see Dimoski, 2016). This is achieved by providing students with transcripts of listening texts and allowing them to read the texts aloud to each other in pairs. Rather than receiving the listening text via technology (e.g., a CD player), which students have no control over, the auditory input comes from a fellow human being (i.e., a classmate).

According to Björkman (2010), "monologic events, where the listener has few opportunities, if any, to check his / her own understanding, are where misunderstandings and general comprehension problems are most likely to occur" (p. 85). Thus, PAL allows the listener to interact with the listening source when non-understanding occurs through the application of CSs to negotiate meaning with the speaker (i.e., their partner). PAL also enables the speaker, while playing the role of the person whose transcript is being read aloud (and displaying a picture of the person to create a sense of realism), to repeat or reformulate information to accommodate the listener. Hence, unlike traditional models based on monologic speech, which require students to listen passively for extended lengths of time (Björkman, 2010), PAL creates opportunities for students to work collaboratively to negotiate and co-construct meaning.

In ELF-aware pedagogy, including in this study in which all the subjects were Japanese, the features of PAL are significant. According to Kaur (2014), collaborative class work such as role plays that mimic ELF-type scenarios, particularly if realistic, can generate valuable opportunities for learners to practice a variety of CSs. Björkman (2010) acknowledged that interactive speech events incorporating CSs and "proactive work that enhances understanding and prevents misunderstanding ... [are] very useful communicative behavior" (p. 86). Clearly then, in ELForiented pedagogy, LC that is pro-active is a step in the right direction, and even more so when the content that students are negotiating comes from non-native English speakers from a different culture.

Importantly, the PAL approach is not a replacement of traditional LC, but an alternative. Educators, based on their learners' needs, can judge whether to employ traditional LC, PAL, or both (Dimoski, 2016). In this study, traditional-type LC was used in a pre-PAL activity to 
expose students to non-native accents and varieties of English since, in terms of Wen's (2012) linguistic objectives, "students are expected to understand what non-native speakers say in English" (p. 374).

To the authors' knowledge, no other research has attempted to combine these two approaches, thus making this the first empirical study to incorporate the PAL approach proposed by Dimoski (2016).

\section{Research Aims}

This study aims to explore students' ability to communicate effectively during PAL comprehension activities in an intercultural context, both prior to and upon completion of explicit CS training. To investigate this, the study seeks to answer the following research questions:

1. What effect does explicit teaching of CSs have on students' perceived ability to use CSs effectively?

2. Does the explicit teaching of CSs enable students to become more competent communicators during PAL activities?

3. What influence do students perceive an ELF-informed intercultural framework incorporating PAL and CSs has on their communication skills?

\section{Participants}

\section{Methodology}

Participants in the study consisted of 53 first-year and second-year university students ranging from 18 to 19 years of age from three classes within the ELF program. Fifteen participants (5 males, 10 females) were second-year students in the ELF 301 (intermediate level) class from the Department of International Management, while the remaining 38 participants (19 males, 19 females) were freshmen in two ELF 202 (lower-intermediate level) classes. Students in one of the ELF 202 classes were from the Department of Education, and in the other, all students belonged to the Department of International Management. Students are placed in levels when they enter the program based on TOEIC Bridge scores, corresponding to TOEIC IP test scores of 400-449 for ELF 202 and 450-509 for ELF 301. Typically, Japanese university students have accumulated six years of experience studying English as a subject prior to entering university.

Because this study incorporated potentially challenging authentic listening texts, the authors selected their highest-level classes for the study. These classes were also conducted during the same period, thus allowing the authors to combine all three classes on three occasions.

Importantly, all 53 students were willing participants in the study and provided their written consent prior to the commencement of the project.

\section{Data Collection}

The data was triangulated to help to deepen understanding, minimize potential bias, and increase validity of the data (Olsen, 2004). Data collection in this study included (a) the administering of a pre- and post-practice Likert-type scale questionnaire to all participants and analysis of the responses; (b) the recording, transcription, and analysis of 12 randomly selected participants' dialogical speech; and (c) the analysis of all participants' post-project reflections written in English or in Japanese. 
Pre- and post-practice questionnaire. The authors developed a pre- and post-practice questionnaire featuring a five-point Likert-type scale (see Appendix A), ensuring all of the participants were asked "precisely the same questions in an identical format and responses. . . [were] recorded in a uniform manner" (Boynton \& Greenhalgh, 2004, p. 1313) to increase its reliability. The questionnaire was administered to elicit responses from students regarding their perceived ability to use six CSs effectively and their overall ability to use CSs. For each of the seven items, five responses were provided: Strongly disagree, Disagree, Neutral, Agree, and Strongly agree. All Japanese translations in the questionnaire were written by one of the authors, a native Japanese speaker, and then checked by another native Japanese speaker. Before commencing the CS training sessions, the students responded to all seven items to establish their perceived pre-practice ability to use the CSs effectively. Upon completion of each of the training sessions, students responded to the respective item in the post-practice section. Data and statistics derived from the questionnaire results are descriptive and were used to observe general outcomes.

CS training sessions. CS training consisted of six sessions, each lasting approximately 30 to 45 minutes. The CSs included CS A, asking for confirmation; CS B, asking for repetition; CS C, asking for confirmation of word meaning; CS D, asking for clarification of sentence meaning; CS E, paraphrasing; CS F, using body language; and CS G, overall use of the strategies. These CSs are relevant to ELF contexts (for CSs A to E, see Björkman, 2014; for CS F, see Dimoski, 2016).

Regarding materials used in all the activities during this project, efforts were made to maintain consistency. Original materials, developed specifically for the CS training sessions, consisted of information-gap-type activities designed for students to focus on one strategy per session. The worksheet for CS E incorporated elements reflective of PAL practice (see Appendix B).

Because research for this study was conducted during regular class periods with fixed schedules, opportunities for the authors to combine their classes were limited. It was possible to combine 100-minute classes on three occasions, however, which helped to minimize variability in the data collected. The training session for CS A was conducted in the first combined class on December 9, 2015, following collection of pre-CS training dialogic data during the first half of the lesson. Training for CS E was done in the second combined class on December 21. A final training session to review all of the strategies (CS G) was conducted during the third combined class on January 13,2016, prior to collection of post-CS training dialogic data during the latter half of the lesson. CSs B, C, D, and F were taught by the authors in their individual classes, using the same lesson material to maximize consistency.

Recording and transcription of dialogic speech. The second phase of this project involved the audio and video recording of students' dialogic speech during combined classes on two occasions, once on December 9, 2015 prior to the explicit teaching of CSs, and once on January 13, 2016 after all of the CS training sessions had been completed. For data collection during PAL, six randomly selected student pairs (A1 / B1 to A6 / B6) were placed in a separate room at the same time, where their interactions were recorded for later analysis. Students were not informed that they would be asked to repeat the same process in January. In the January combined class, Student A1 was absent, thus only student pairs A2 / B2 to A6 / B6 were recorded. Subsequently, data collected from student pair A1 \& B1 during the first combined class was excluded from this study.

To ensure consistency in the data, all students (including the six student pairs) were assigned the same partners in both the pre- and post-training combined classes. It may be worth noting 
that the two combined classes involving recorded interactions during PAL activities did not share the same theme, with the first being "discrimination" and the second "past and future dreams." The authors contend that the difference in themes had no significant bearing on their findings, since the focus of this study was not the frequency of non-understandings, but the responses by students to non-understandings.

PAL comprehension activities. PAL comprehension activities were the source of dialogic speech for data collection in the study. This interactive component enabled the authors to transform LC into a more authentic dialogic speech event.

Videos containing monologic speech about discrimination and past and future dreams by ELF users from Ethiopia, Holland, and Venezuela and a native English user from South Africa were transcribed and used for the PAL component in the combined classes. The videos come from the website 7 billion Others (www.7billionothers.org).

Post-project written reflections. The third source of data was students' written reflections. A form containing several questions, which students could answer in English or Japanese, was handed out at the end of the final joint session. The questions asked students whether their communication skills had improved and in what ways. Students were also asked to write their overall reflections on the improvement of their own CSs.

\section{Pre- and Post-Practice Student Questionnaire}

\section{Results and Findings}

From the averages of the pre- and post-practice questionnaire responses, there is an overall increase in students' perceived ability to use the CSs effectively after receiving CS instruction (see Table 1). Prior to the explicit teaching of the CSs, students identified CS A (asking for confirmation, 3.08), D (asking for clarification of meaning on a sentence-level, 3.04), E (paraphrasing, 2.44), and G (overall use of the strategies together, 2.54) as the items they are least effective in using. From the post-data, the greatest differences between pre- and postaverage percentages in students' perceived ability to use the CSs effectively occurred with CS D (asking for clarification of meaning on a sentence-level, 20\%), E (paraphrasing, 20.6\%), F (using body language, $19.4 \%$ ), and G (overall use of the strategies together, 20\%). An average response of 4.13 (out of 5) reveals that students perceived they can use CS F the most effectively.

Upon closer inspection, the data on students' belief that they can use all the strategies together reveals there was a relatively large number of students (23) who either strongly disagreed or disagreed they were effective in using CS G initially. There was also a similar number of students who gave a neutral response. In the post-practice results, the majority of students (24) agreed or strongly agreed with the same item. This shift suggests that most of the participants' confidence in using CSs increased. 


\section{Table 1}

Results of Student Questionnaire for Pre and Post CS Training

\begin{tabular}{|c|c|c|c|c|c|c|c|c|c|c|}
\hline Communication Strategy & $n$ & $\begin{array}{c}\text { Pre / } \\
\text { Post } \\
\text { Practice }\end{array}$ & SD & $\mathrm{D}$ & $\mathrm{N}$ & $A$ & SA & Avg & $\begin{array}{l}\text { Avg } \\
\text { Percent }\end{array}$ & $\begin{array}{l}\text { Pre / Post } \\
\text { Practice } \\
\text { Difference }\end{array}$ \\
\hline \multirow{2}{*}{$\begin{array}{l}\text { A. I can ask for confirmation } \\
\text { effectively. }\end{array}$} & 50 & Pre & - & 8 & 32 & 8 & 2 & 3.08 & $61.6 \%$ & \\
\hline & & Post & 1 & 6 & 15 & 26 & 2 & 3.44 & $68.8 \%$ & $7.2 \%$ \\
\hline \multirow{2}{*}{$\begin{array}{l}\text { B. I can ask for repetition } \\
\text { effectively. }\end{array}$} & 50 & Pre & - & 5 & 30 & 11 & 4 & 3.28 & $65.6 \%$ & \\
\hline & & Post & - & 3 & 9 & 27 & 11 & 3.92 & $78.4 \%$ & $12.8 \%$ \\
\hline \multirow{2}{*}{$\begin{array}{l}\text { C. I can ask for } \\
\text { confirmation of word } \\
\text { meaning effectively. }\end{array}$} & 47 & Pre & - & 5 & 26 & 12 & 4 & 3.32 & $66.4 \%$ & \\
\hline & & Post & - & - & 17 & 20 & 10 & 3.85 & $77 \%$ & $10.6 \%$ \\
\hline \multirow{2}{*}{$\begin{array}{l}\text { D. I can ask for clarification } \\
\text { of sentence meaning } \\
\text { effectively. }\end{array}$} & 48 & Pre & - & 11 & 27 & 7 & 3 & 3.04 & $60.8 \%$ & \\
\hline & & Post & - & 1 & 12 & 19 & 16 & 4.04 & $80.8 \%$ & $20 \%$ \\
\hline \multirow{2}{*}{$\begin{array}{l}\text { E. I can use paraphrasing } \\
\text { effectively. }\end{array}$} & 43 & Pre & 1 & 25 & 15 & 1 & 1 & 2.44 & $48.8 \%$ & \\
\hline & & Post & 1 & 4 & 17 & 16 & 5 & 3.47 & $69.4 \%$ & $20.6 \%$ \\
\hline \multirow{2}{*}{$\begin{array}{l}\text { F. I can use body language } \\
\text { effectively. }\end{array}$} & 45 & Pre & 1 & 9 & 19 & 14 & 2 & 3.16 & $63.2 \%$ & \\
\hline & & Post & - & 1 & 8 & 20 & 16 & 4.13 & $82.6 \%$ & $19.4 \%$ \\
\hline \multirow{2}{*}{$\begin{array}{l}\text { G. I can use all of the } \\
\text { strategies together } \\
\text { effectively. }\end{array}$} & 46 & Pre & 3 & 20 & 18 & 5 & - & 2.54 & $50.8 \%$ & \\
\hline & & Post & - & 3 & 19 & 20 & 4 & 3.54 & $70.8 \%$ & $20 \%$ \\
\hline
\end{tabular}

Note. $\mathrm{SD}=$ Strongly Disagree, $\mathrm{D}=$ Disagree, $\mathrm{N}=$ Neutral, $\mathrm{A}=$ Agree, $\mathrm{SA}=$ Strongly Agree. Only data from students who responded to the items in both the pre and post practice sections of the questionnaire appear in the results above.

\section{Analysis of Recordings and Transcriptions of Dialogic Speech}

The sets of transcriptions for two pair-groups are provided in Appendix C. The first transcriptions (1.1 and 2.1) were recorded prior to the teaching of CSs and the second transcriptions (1.2 and 2.2) were recorded after all of the CS training sessions were done.

Transcription 1.1 shows a conversation between two ELF-202 students (A4 and B4) from different classes prior to the explicit teaching of CSs and PAL comprehension activity practice. It immediately represents how unsuccessful the communication was due a lack of competence in CS use by both the speaker and the listener. Student B4 used silence while smiling, a type of non-verbal communication, which is an acceptable response for expressing non-understanding in Japan but could be interpreted differently across cultures. Student A4 ended the communication by simply showing the answer on the paper.

The same pair of students met after completing all of the CS training sessions. In Transcription 1.2 , there was notable improvement. For example, Student B4 immediately used a gesture to stop Student A4 in a timely manner and also used a clarification strategy by repeating a word Student B4 did not understand. Both students still need more practice to be able to ask for clarification in full questions such as "What does nightmare mean?" However, this data shows that Student B4 started using CS strategies early in the conversation rather than being silent and giving up on the activity.

The second set of transcriptions shows overall improvement in two ELF-202 students' use of strategies to continue their conversation. Transcription 2.1 shows that Student A2 asked a question and Student B2 smiled, indicating the student did not know what to answer. This is the same type of reaction seen in Transcription 1.1. Transcription 2.1 shows ineffective communication similar to that of the first pair. However, Transcription 2.2 demonstrates the pair's clear progress in conveying messages to each other. Student B2 immediately stopped 
Student A2's speech to ask for the meaning of a word. Student A2 replied by using a paraphrasing strategy, stating the meaning in different words. The students continued to show improvement in communication using CSs. Importantly, Student B2 was able to formulate full sentences when asking for clarification and repetition during PAL comprehension activities following the CS training sessions.

\section{Student Reflections}

In reference to the third research question, the majority of students' written reflections (see Appendix D) indicate this project had a positive influence on their communication skills. Some concerns, however, were also raised. Reflection 7 states that combining students of mixed levels from different departments was a demotivating factor due to a perceived lack of participation and ability of some non-Education Department students.

Two of the students' written reflections excerpted below (Reflections 1 and 2) were originally written in Japanese and translated into English by one of the authors, a native Japanese speaker, and then checked by another native Japanese speaker. The first comment shows a positive attitude to the CS training methodology.

Through the CS lessons, I could learn the phrases I can use in a daily conversation. I know these English expressions but I can't say them instantly, so this was a good opportunity. (Reflection 1)

The authors' interpretation is that before the project, this student felt more practice was needed to be able to use CSs effectively. However, through this project, the student learned how to use these expressions to continue the conversation.

Reflections 2 and 3 suggest the students recognize that instead of strict adherence to native English norms, intelligibility is of primary importance.

I am poor at conveying what I am thinking, but through these lessons, I learned that I should respond even if the response is not perfect rather than remain silent. (Reflection 2)

Yes, I think that my communication skills have improved. Because I couldn't explain well in English, but I was able to tell and to understand. I felt that to repeatedly listen is important. (Reflection 3)

The comments are reflective of ELF-informed thinking, and raising learner awareness of such concepts is one of the main aims of the CELF.

Reflection 4 relates to the intercultural component of the third research question by highlighting a difference (as viewed by the student) between Japanese and English-speaking culture.

It came to be conveyed that I expressed what I wanted to say using gesture . . . and I devised it so that a partner understood it. . . The Japanese rarely gave a gesture to a conversation. However, I learned when the gesture was very effective! (Reflection 4)

The student realized the importance of using gestures (CS F) when communicating in ELF settings and observed that, even though Japanese rarely use gestures, trying to explain with 
gestures enhanced communication skills. Hence, the ELF-informed intercultural framework used in this study had a positive influence on the student.

\section{Discussion}

This study investigated, from an ELF perspective, the importance of teaching CSs and creating opportunities for students to use them in ELF-like situations through PAL activities to develop their ability to negotiate meaning and overcome non-understanding when it occurs. From the student questionnaire, a significant outcome can be observed, with over half of the CSs (D, E, F, G) resulting in a 20 percent or more increase in students' perceived ability to use CSs effectively following the training sessions. Students became aware of the importance of using CSs, and they made efforts to use them appropriately during PAL activities.

The transcriptions and reflections demonstrate other ways in which students' communication skills improved. Students' realization that silence is an ineffective (pragmatic) strategy (Reflection 2), despite its general acceptance in Japan (Harumi, 1999) and that body language can enhance communication (Reflection 4), even though (according to the student) Japanese rarely use gestures, suggest a heightened student awareness of "general rules of communication that underlie particular realizations in different countries and cultures" (Wen, 2012, p. 375).

There are some limitations in this research worth noting. First, the study was conducted over a relatively short period. Thus, longitudinal research together with more quantitative data to support the authors' claims should be presented. The Likert-type scale questionnaire is another potential limitation. Since students were asked to respond to an individual item at the end of each training session, the timing may have influenced their responses. A lack of familiarity during the initial sessions may have had an adverse effect students' confidence and limited their ability to use the CSs effectively. This may account for the lower post-treatment questionnaire responses observed for CSs A, B, and C. Similarly, unfamiliarity with the PAL activities in the first combined class may have reduced students' ability to use CSs effectively. Moreover, as previously noted, the combining of different class levels and departments may have had an adverse effect on some students' performance. Lastly, because the study was conducted in a structured classroom (i.e., non-authentic) environment, positive outcomes observed in this study may not necessarily translate to students' actualability to use CSs effectively in real-world, ELF or otherwise, situations.

Interestingly, written reflections from students such as "I learn about pronunciation ..." (Reflection 11), "I was able to be conscious of the pronunciation, too" (Reflection 12), and "I felt ashamed that I have bad pronunciation" (Reflection 3) show that even though pronunciation was not one of the objectives in this study, this linguistic element was naturally realized by some participants. Future research into the relationship between pronunciation and explicit CS training could be a worthwhile pursuit for ELF-informed pedagogy. Further research of integrating CSs in ELF-informed curricula to observe quantitative and longitudinal data should also be pursued.

\section{Conclusion}

In conclusion, the data show that explicit teaching of CSs and PAL in an ELF-informed curriculum can be beneficial for students. In students' reflections, they expressed a lack of confidence in communicating in English before the CS training sessions. However, during PAL activities, their confidence showed improvement at the end of the project. This gain is further evidenced by students' ability to overcome non-understanding in a timely manner during PAL 
activities following the CS training sessions. Finally, based on all the above, the authors posit that, through this project, students learned the effectiveness of using CSs.

As Smit (2010) stated, ELF is a "more immediate mode of exchange, with each participant relying directly and immediately on the other one's contribution" (p. 57), so it is crucial for ELF learners to focus on learning CSs to successfully partake in dialogue. This needs to be taught explicitly by teachers and practiced by students in class using PAL comprehension activities. In the absence of such practice, students may fail to recognize the importance of CSs and assume that, unless they adhere strictly to native English norms, they cannot become effective communicators in English. The authors contend it is up to individual programs to change students' perspectives on language learning for ELF competence.

\section{Author Note}

Blagoja Dimoski, Yuri Jody Yujobo, and Mitsuko Imai, Center for English as a Lingua Franca (CELF), Tamagawa University; Tokyo, Japan.

Blagoja Dimoski teaches at Tamagawa University. He holds an MA in Applied Linguistics from the University of Queensland and a Graduate Certificate in Second Language Teaching from Griffith University. His research interests include cross-cultural understanding, pragmatics, learner development, and utilizing technology in the classroom to enhance student learning.

Yuri Jody Yujobo teaches at Tamagawa University. She is a Japanese-American and holds an M.Ed in TESOL. Her research interests include active learning, Project-Based Learning, $21 \mathrm{st}$ Century Skills, and bilingualism. Previously, she worked in global human resource development and trained Japanese employees on international skills.

Mitsuko Imai teaches at Tamagawa University. She has an MA TESOL. Her research interests include autonomy, motivation, blended learning, and bilingualism. Her recent research focuses on training in autonomy and explores ways to incorporate technology to enhance autonomous learning in university curricula.

Correspondence concerning this article should be addressed to Blagoja Dimoski, Center for English as a Lingua Franca, Tamagawa University, 6-1-1 Tamagawagakuen, Machida, Tokyo, Japan. E-mail: bdimoski@lit.tamagawa.ac.jp 


\section{References}

Björkman, B. (2010). So you think you can ELF: English as a lingua franca as the medium of instruction. Hermes - Journal of Language and Communication Studies, 45, 77-96.

Björkman, B. (2014). An analysis of polyadic English as a lingua franca (ELF) speech: A communicative strategies framework. Journal of Pragmatics, 66, 122-138. https://doi.org/10.1016/j.pragma.2014.03.001

Boynton, P. M., \& Greenhalgh, T. (2004). Selecting, designing, and developing your questionnaire. BMJ, 328(7451), 1312-1315. https://doi.org/10.1136/bmj.328.7451.1312

Burch, A. R. (2014). Pursuing information: A conversation analytic perspective on communication strategies. Language Learning, 64(3), 651-684. https://doi.org/10.1111/lang.12064

Canagarajah, S. (2006). Changing communicative needs, revised assessment objectives: Testing English as an international language. Language Assessment Quarterly, 3(3), 229-242. https://doi.org/10.1207/s15434311laq0303_1

Choi, K., \& Jeon Y. J. (2016, February). Suggestion on teachers' beliefs research on teaching English as a lingua franca. Paper presented at the 2016 International Conference on Platform Technology and Service (PlatCon), Jeju, South Korea. Abstract retrieved from https://doi.org/10.1109/PlatCon.2016.7456828

Cogo, A., \& Dewey, M. (2012). Analysing English as a lingua franca. London, UK: Continuum. https://doi.org/10.1515/jelf-2012-0020

Dimoski, B. (2016). A proactive ELF-aware approach to listening comprehension. The Center for ELF Journal, 2(2), 24-38. Retrieved from http://libds.tamagawa.ac.jp/dspace/bitstream/11078/363/1/2-2-3.pdf

Graddol, D. (2003). The decline of the native speaker. In G. Anderman \& M. Rogers (Eds.), Translation today: Trends and perspectives (152-167). Clevedon, UK: Multilingual Matters.

Harumi, S. (1999). The use of silence by Japanese learners of English in cross-cultural communication and its pedagogical implications (Doctoral dissertation). Institute of Education, University of London, London, UK.

Kaur, J. (2014). Teaching the effective use of ELF: Insights from research into ELF pragmatics. WASEDA Working Papers in ELF (English as a Lingua Franca), 3, 158-168.

Kaur, J. (2016). Using pragmatic strategies for effective ELF communication: Relevance to classroom practice. In K. Murata (Ed.), Exploring ELF in Japanese academic and business contexts: Conceptualization, research and pedagogic implications (pp. 241-254). Oxon, England: Routledge.

Mauranen, A. (2012). Exploring ELF: Academic English shaped by non-native speakers. Cambridge, UK: Cambridge University Press.

Min, B.-c., \& Reagan, N. (1994). Ugly Japanese, Ugly Americans. Seoul, South Korea: BCM Publishing \& Language Center.

Olsen, W. (2004). Triangulation in social research: Qualitative and quantitative methods can really be mixed. In M. Holborn (Ed.), Developments in sociology (pp. 103-118). Ormskirk, England: Causeway Press.

Seidlhofer, B. (2011). Understanding English as a lingua franca. Oxford, UK: Oxford University Press.

Smit, U. (2010). English as a lingua franca in higher education. Berlin, Germany/New York, NY: De Gruyter Mouton. https://doi.org/10.1515/9783110215519

Wen, Q. (2012). English as a lingua franca: A pedagogical perspective. Journal of English as a Lingua Franca, 1(2), 371-376. https://doi.org/10.1515/jelf-2012-0024 


\section{Appendix A \\ Pre- and Post-Practice Questionnaire}

Student Name:

Student No:

Class:

Teacher's Name:

\section{Communication Strategies (CSs): Step-by-Step}

Just as a life preserver helps you survive in deep water by keeping you alloat, communication strategies (CSs) enable you to communicate more effectively and stay afloat when you encounter English that is over your head.

1) Below is a list of CSC (A F) that you will practice in your Elf class.

A: Asking for confirmation

(words / numbers) 單䃌と数の確现をとる

D: Asking for clarification

(sentence-meaning)

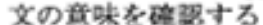

\section{B: Asking for Repefition}

もう一度闑きなお方

E: Using Paraphrasing

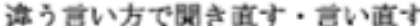

\section{C: Asking for confirmation}

(word-meaning)

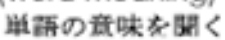

F: Using Body Language ジェスチャー・・表情老使う

2) Use the questionnaire below to record your a) pre-practice ability, b) scores, and c) post-practice ability to use CSs.

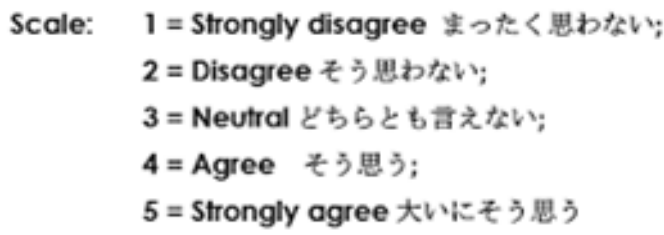

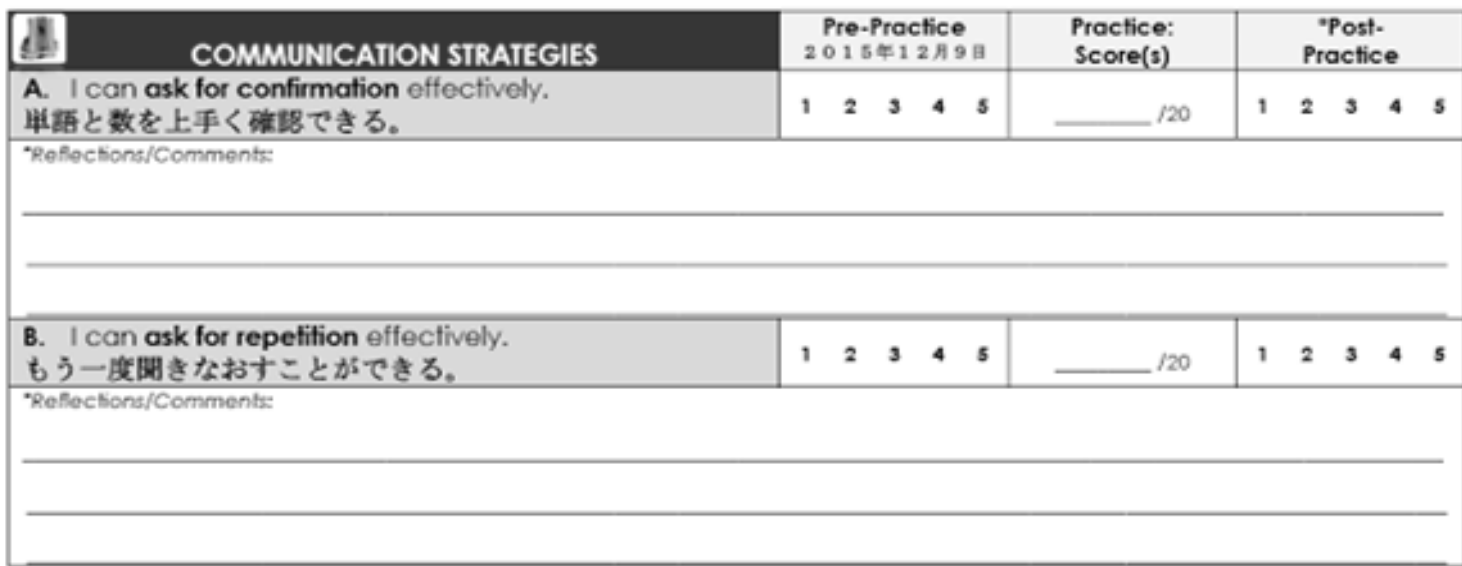




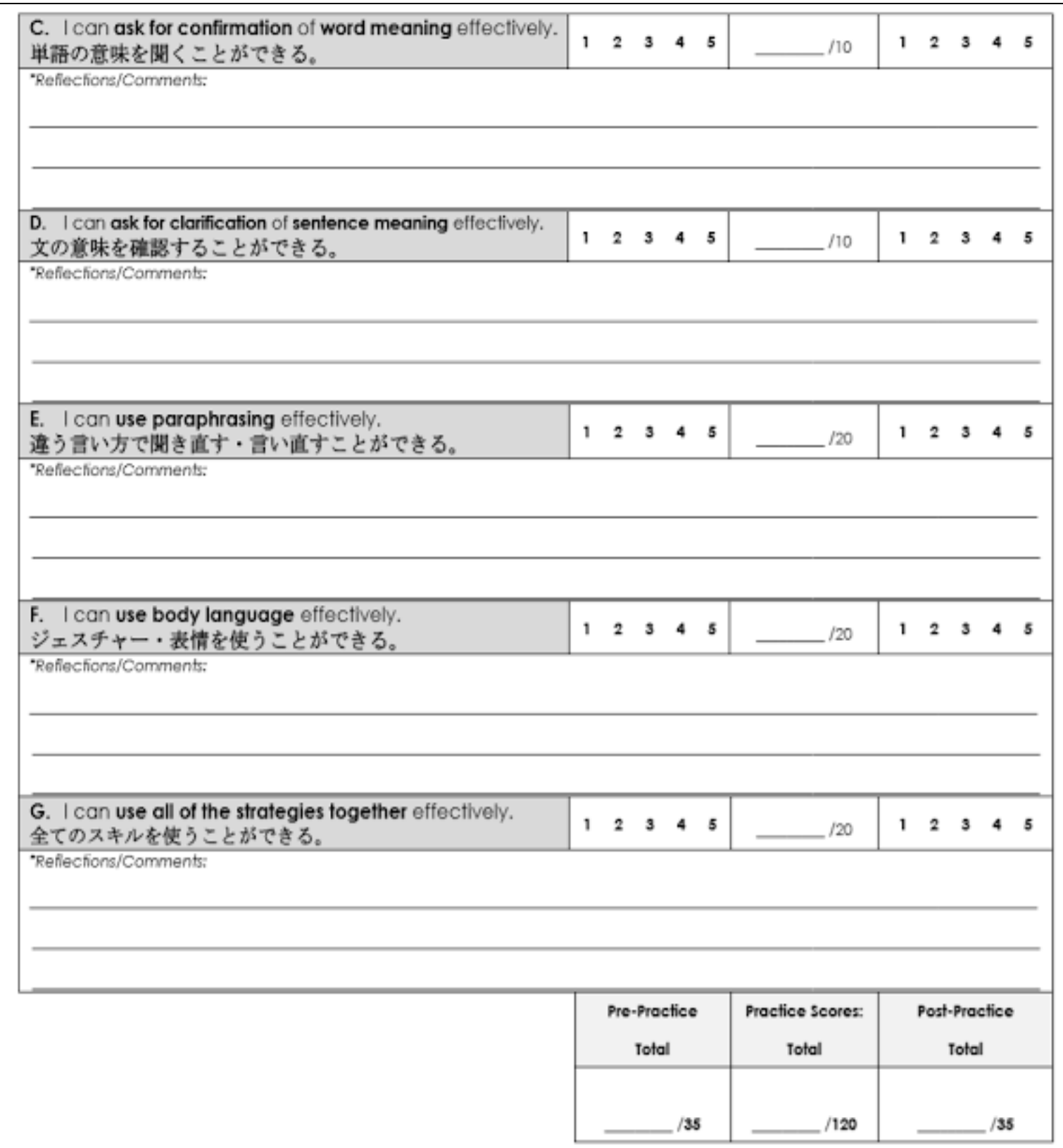

Note. The Japanese translations were written by one of the authors, a native Japanese speaker, and then checked by another native Japanese speaker. Students were not required to record their practice scores (i.e., it was optional). 


\section{Appendix B \\ Sample of CS E Worksheets}

Communication Strategies: Step-by-step DON'T FORGET TO USE PREVIOUS STRATEGIES

\begin{tabular}{|c|c|}
\hline Strategy A & Strategy B \\
\hline 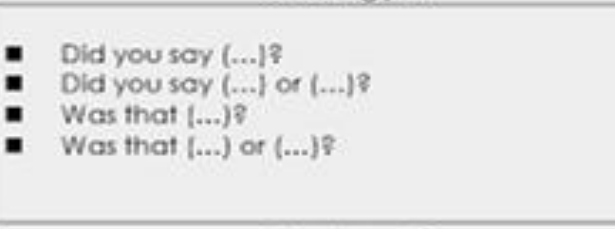 & 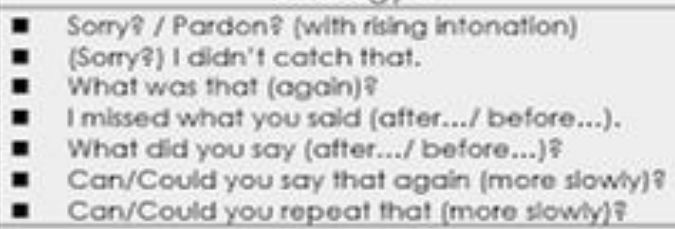 \\
\hline Strategy C & Strategy D \\
\hline $\begin{array}{l}\text { - (Do) you mean (wave) like/as in (wave } \\
\text { - goodbye)? } \\
\text { (Do) you mean (wave) like/as in (wave } \\
\text { goodbyo) or (wavo) like/as in (an ocean } \\
\text { wave)? }\end{array}$ & $\begin{array}{l}\text { What does }(\ldots) \text { mean? } \\
\text { What do you mean by }(\text {...)? } \\
\text { - Sorry. I don't know what }[\text {...) means. } \\
\text { What do you mean, for oxamplo? } \\
\text { - Repeat the word/sentence with rising } \\
\text { intonation. }\end{array}$ \\
\hline
\end{tabular}

\section{TODAYS NEW STRATEGY}

\section{STRATEGY E: Paraphrasing (to express understanding)}

\section{EXAMPLES:}

Statement: Skydiving isn't safe.

Parophrase $\rightarrow$ H's a dangerous sport.

Statement: It's a beautiful day.

Paraphrase $\rightarrow$ The weather todoy is really nice.

Statement: Japan isn't as big as America.

Parophrase $\rightarrow$ The U.S. is larger than Jepan.

\section{POINTS SYSTEM}

O = Many (or all) different words are used. (= 2 points)

$\Delta=$ some different words ore used. ( 1 point)

$X=$ One (or no) different words ore used ( $=0$ points)

Example Dialogue:

A: Skydiving isn't safe.

O B: That's right. It's a dangerous sport. (= 2 points)

$\triangle B:$ il think skycliving is dangerous, too. (= 1 point)

$\times$ B:l agree. It isn't sate. ( 0 points)

A: I's a beautiful day.

\section{Practice Using Paraphrasing (to express understanding)}

A) Read the 5 STATEMENTS bolow to your partner. Atter each one, your partner should paraphrase the statement you read. USTEN and use the symbols $(O \triangle X)$ next to each statement to check your partner's porophrosing. De NOI atop unless your partner uses communicotion strotegies.
1. Shopping in Ginza isn't cheap. $\rightarrow$ Studeat B's score: $O \Delta \times$
2. Kanji isn't easy to learn. $\rightarrow$ Student Bs score: $O \Delta \times$
3. Pizza tastes really good. $\rightarrow$ Studeat B's scare: $O \Delta \times$
4. Natto is good for your body. $\rightarrow$ Student Bs scorv: $\triangle \triangle \times$
5. Disneyland is very crowded during the winter holidays. $\rightarrow$ Student B's score: $\bigcirc \Delta \times$
". After you finish all the statements. tell your partner his or her points for each paraphrase.".

B) Your partner will say 5 STATEMENTS. Listen and PARAPHRASE after each statement. Yout partnet will NOI stop unless you use communication strategies.

"When you finish, ask your portner your score for each poraphrose. Use the symbols below.".

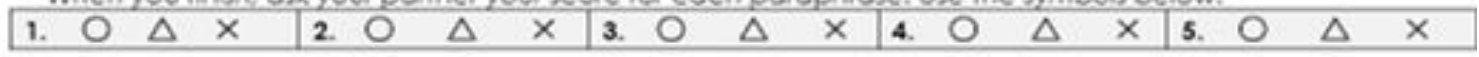

Write your score. (2. 1. or 9 points for each porcphrase)

My score WITH CSs: /10 


\section{STRATEGY E: Paraphrasing (to clarify meaning)}

EXAMPLES:

- What I mean is $(\ldots)$.

- What I'm saying is $\{\ldots\}$.

- In other words, (...).

- For example, $(\ldots)$.
EXAMPLE DIALOGUE:

A: Did you know that "Americans in Japan frequently find themselves being asked questions on topics they consider to be private?

B: $\ldots 2^{2} \ldots$ ? ...?

A: Do you know what I mean?

B: Sorry, no I don't.

A: What I mean is Americans think that Japanese people ask too many personal questions.

B: Oh, really? I didn't know that.

"Excerpt from "Ugly Japanese, Ugly Americans" by Min Byoung-chu \& Nevitt Rezgan (1994, p. 45)

\section{Practice Using Paraphrasing (to clarify meaning)}

A. Read the fext below about cultural differences between America and Japan.

Did you know that Japanese people think it is strange when Americans...

\section{•Brag about themselves.}

"In the U.S., one is expected to promote one's own accomplishments, to "blow one's own horn."

To Japanese, who prefer a more self-effacing and humble approach, this seems very arrogant.

"Excerpt from "Ugly Japanese, Ugly Americans" by Min Byoung-chu \& Nevitt Reagan (1994, p. 120)

B. Look at the questions below. You will answer them AFTER you finish section D.

1. What do Japanese people dislike about the way Americans communicate?

2. Why do Japanese people dislike it?

3. Why do American people communicate that way?

4. How do Japanese people prefer to communicate?

\section{EXAMPLE DIALOGUE}

A) Did you know that Japanese people don't like if when Americans prag about themselves?

B) What do you mean, "they brag about themselves"?

A) What I'm saying is, "Americans like to talk about themselves:"

B) On, I see. Thank you. (Student B WRITES $\rightarrow$ "Americans like to talk about themselves.") 
D. Now practice with Student B.

1. 19 READ Statement: "In America, one is expected to promote one's own accomplishments. 2nd WAIT for Studiont B's response.

34 READ Paraphrase: What I'm saying is $\rightarrow$ it is normal in America for people to falk about their successes.

2. 13 USTEN to Student B read a statement:

2" ASK Studient B: $\rightarrow$ What do you mean by "to blow one's own horn?

3 WRIIF Student B's paraphrase below:

$\rightarrow$

You don't have to wrife every word.

3. 13 READ Statement: "Japanese prefer a more self-effacing and humble approach. 2nd WAII for Studient B's response.

3 . READ Paraphrase: For example, I mean $\rightarrow$ Japanese like a more quiet and simple (or shy) communication style.

4. 13 USTEN to Student B read a statement:

2 nd ASK Student B: $\rightarrow$ What does "this seems very arrogant mean?

3 . WRITE Student B's paraphrase below:

$\rightarrow$

You don't have to write every word.

"Excerpts from "Ugly Japanese, Ugly Americans" by Min Byoung-chu \& Nevitt Reagan (1994, p. 120)

E. Now go back to SECTION B (above) and ANSWER the 4 questions.

Write your score. (100int for each correct answer)

My score WITH CSs: $/ 4$

\section{More Practice Using Paraphrasing (to clarify meaning)}

F. Read the fext below about cultural differences between America and Japan. Make sure that you understand all of the content.

Did you know that Japanese people think it is strange when "Americans drink directly from a bottle? "Although this may be acceptable behavior in most parts of the world, in Japan it is just not the done thing. With the exception of small juice bottles from vending machines, one nearly always uses a cup or a glass for drinking.

"Excerpts from "Ugly Japanese, Ugly Americans" by Min Byoung-chu \& Nevitt Reagan (1994, p. 109) 
G. Now get ready to READ the text below to Student B. USE PARAPHRASING (some has already been done for you) ONLY when your partner uses communication strateqies (OR when you see that he or she may not understand, e.g. $\rightarrow$ Do you know what I mean? etc.) While you read.

ADD your own notes before you start if you like.

Did you know that Japanese people think it is strange when Americans "drink directly from a bottle? drink from a bottle with your mouth

"Nthough this may be acceptable behavior in most parts of the world, in Japan it is just not the

"done thing. With the exception of small juice bottles from vending machines, one nearly always Japanese people

"uses a cup or a glass for drinking.

"Excerpt from "Ugly Japanese, Ugly Americans" by Min Byoung-chu \& Nevitt Reagan (1994, p. 109)

H. Ask Student B the following questions about the above fext:

1. For Japanese people, what is strange about the way Americans drink? (2 points)

2. Is it only Americans who drink that way? Give me an example. (2 points)

3. When do Japanese people drink the same way as American people do? (2 points)

Check Student B's answers. (Give him or her 2,1 or 0 points for each answer)

I. Now, listen to Student B talk about cultural differences between America and Japan. Your partner WILL NOT SIOP unless you use communication strategies. Student B will ASK YOU 3 QUESTIONS affer he or she finishes reading. You can take notes below if you wish.

Write your score. $[2,1$, or 0 points for each answer)

WITH CSs; $/ 6$

Note. This is a sample of Student A's worksheets used December 21, 2015. The content for Student B is not the same. The worksheets contain excerpts from "Ugly Japanese, Ugly Americans" by Min \& Reagan (1994). 


\section{Appendix C \\ Transcriptions for Each Pair-Group}

\section{Transcription 1.1}

$1<$ A4 $><$ READING $>$ what was my major in university? $<$ READING $></$ A4 $>$

$2<$ B $4><$ P: 05 $><$ USING BODY LANGUAGE: SMILING $></$ B $4>$

$3<$ A4 $><$ SHOWING B4 THE ANSWER ON THE WORKSHEET $></$ A4 $>$

$4<$ B $4><$ READING $>$ engineering $<$ READING $><$ B $4>$

$5<$ A $4><$ USING BODY LANGUAGE: NODDING $><$ READING $>$ what country did

6 I go to university? $<$ READING $></ A 4>$

$7 \quad<$ B4 > <USING BODY LANGUAGE: STRESSFUL LOOK ><LOOKING AT A4's

8 WORKSHEET $><$ READING $>$ (vene), (zu), (ela) $<$ /READING $></$ B4 $>$

$9<$ A44 $><$ A4 $>$ okay $</$ A4 $><$ READING $>$ how well was I qualified for the jobs that I

10 applied for? $<$ READING $></$ A $4>$

$11<$ B4 $><$ LOOKING AT A4's WORKSHEET $><$ READING $>$ she fit

12 perfectly $</$ READING $><$ B $4>$

$13<$ A4 $><$ USING BODY LANGUAGE: NODDING $>@ @</ A 4>$

$14<$ B4 $>@ @<$ B4 $>$

\section{Transcription 1.2}

$1<$ A4 $><$ READING $>$ I had many nightmares many nightmares I probably

2 was $</$ READING $></$ A4 $>$

$3<$ B4 > nightmares? <ASKING FOR CLARIFICATION $><$ USING BODY

4 LANGUAGE: HAND GESTURE FOR STOP $></$ B4 $>$

$5<$ A4 $><$ FOREIGN $>(x x)<$ EXPLAINING IN JAPANESE $><$ /FOREIGN $></$ A4 $>$

$6<$ B4 $>$ nightmares $<$ EXPRESSING UNDERSTANDING $></ B 4>$

$7 \quad<$ A4 $><$ READING $>$ and something very early of being I' $m$ afraid to say it

8 a little bit of a messiah $</$ READING $></$ A4 $>$

$9<$ B4 > messiah? <ASKING FOR CLARIFICATION > <USING BODY

10 LANGUAGE: TILTING HEAD TO EXPRESS NON-UNDERSTANDING>

$11</$ B4 $>$

\section{Transcription 2.1}

$1<$ A2 $><$ READING $>$ I fit perfectly the description of what they were looking for and

2 when I went to turn in my application they told me they were not looking for a

3 female $<$ /READING $></$ A2 $>$

$4<$ B2> <USING BODY LANGUAGE: LOOKING DOWN AT HIS/HER

5 WORKSHEET $></$ B2 $>$

$<$ A2 $>$ question $<$ READING $>$ what was my major in university? $<$ /READING $></$ A2 $>$ $<$ B2 $><$ P: 10><FOREIGN $>$ (wakannai) </FOREIGN > <USING BODY LANGUAGE: SMILING $></$ B2 $>$

$9<$ A2 $><$ FOREIGN $>$ (ah, jyaa) $<$ FOREIGN $>$ next $<$ READING $>$ in which country did

10 I go to university? $<$ /READING $></$ A2 $>$

$11<$ B2 $>$ (vene), venezuela $</ B 2>$

$12<$ A2 $><$ A2 $>$ okay $</$ A2 $><$ READING $>$ how well was I qualified for the jobs I

13 (apleed), applied for? $<$ READING $></$ A2 $>$

$14<$ B2> . I don't know <BODY LANGUAGE: SMILING $></ B 2>$ 


\section{Transcription 2.2}

$1<$ A2 $><$ READING $>$ I have many nightmares many nightmares $</$ READING $></$ A2 $>$

$2<$ B2> nightmare?, nightmare? [ASKING FOR CONFIRMATION: WORD-

$3 \quad$ MEANING] $</$ B $2>$

$4<$ A2 $>$ yeah, bad dream, bad dream $<$ PARAPHRASING $></$ A2 $>$

$5<$ B2> bad dream, bad dream <REPEATING: EXPRESSING

6 UNDERSTANDING $></$ B2 $>$

$7<$ A2 $><$ READING $>$ I probably was very depressed $</$ READING $></$ A2 $>$

$8<$ B2> depressed? <ASKING FOR CONFIRMATION: WORD-MEANING>

$9</$ B $2>$

$10<$ A2 $>$ depressed $<$ REPEATING $></$ A2 $>$

$11<$ B2> What do you mean? <ASKING FOR CLARIFICATION: SENTENCE-

12 MEANING $></$ B2 $>$

13 < $2><$ P: 05> <USING BODY LANGUAGE: EXPRESSING SAD EMOTION>

$14</ \mathrm{A} 2>$

$15<$ B2 $><$ B2 $>$ okay, okay, okay $<$ B $2>$ depressed $<$ EXPRESSING

16 UNDERSTANDING $></$ B $2>$

$17<$ A2 $><$ READING $>$ but my dream was very normal to be the moon to be on the

18 moon $</$ READING $></$ A2 $>$

$19<$ B2> sorry sorry sorry, could you repeat more slowly, could more slowly?

$20<$ ASKING FOR REPETITION $></$ B2>

Note. ELFA Transcription Guide. http://www.helsinki.fi/englanti/elfa/ELFA\%20transcription\%20guide.pdf 


\section{Appendix D \\ Sample of Student Reflections}

\section{Instructions}

Reflect on your experience of the three joint lessons. Do you think your communication skills have improved? What kind of improvement and why are strategies helpful for ELF students?

\section{Reflection $1^{*}$}

Through these joint lessons, I learned pronunciation of different teachers and teaching method. I learned a lot from working with students from other classes. Through the CS lessons, I could learn the phrases I can use in a daily conversation. I know these English expressions but I can't say them instantly, so this was a good opportunity. It was also a good opportunity to listen to non-native English speakers through the videos. It was a good learning opportunity. I learned so many expressions so I hope I will have opportunity to use them in the future.

\section{Reflection $2^{\star}$}

I don't hate English, but I cannot say that I am good at it. Even if I can read and listen English, I am poor at conveying what I am thinking, but through these lessons, I learned that I should respond even if the response is not perfect, rather than remain silent. After entering university, I spent more time on other subjects so I am losing my English. Even during this spring semester, I'll try to study English every day. Thank you.

\section{Reflection 3}

I realized how important command of English is. Because I partnered intelligent girl. I am one year her senior, but I'm not as smart as her. She is good pronunciation. I felt ashamed that I have bad pronunciation. So I was helped by strategies. Yes, I think that my communication skills have improved. Because I couldn't explain well in English, but I was able to tell and to understand. I felt that to repeatedly listen is important. We haven't gotten quite use to English. So we can't to use English well. But if we used the strategies, we could tell our opinions. To use the strategies help our communication.

\section{Reflection 4}

I think that I was able to improve a communication skills. I was better at the communication than the reading and writing. It was possible with a fresh feeling by always doing it with a different person. And, I was able to get joy and sense of accomplishment when I got communication. In addition, I was able to have confidence toward a communication skill by this class more. It came to be conveyed that I expressed what I wanted to say using gesture. While BooBoo means that I told, this performs a gesture. And, I devised it so that a partner understood it. In addition, I think that I watched the reaction of the partner well to be important. The Japanese rarely gave a gesture to a conversation. However, I learned when the gesture was very effective! This class had a good experience for me very much! It was from a textbook and was able to learn that I could not learn. I make use of the skills that I learned and want to take the communication from now on.

\section{Reflection 5}

I felt that communication skills very important. It was good to be able to talk with many students. The first is a tense. Because it is a matter weak point to talk. I want to be able to speak more English. I want to study English very harder about reading, writing and lisning. My partner cooperate. So, I was saved very much. Three joint lesson are very difficult. but I think I have a power. I used a gesture, changed an expression and exerted myself. I am glad to have special classes. I wanted to study more in three joint lesson. I want to do my best to talk better. 


\section{Reflection 6}

I think that a communication skill is very important. I was able to confirm importance by doing this join class. There is different how to convey even if I do not understand English. I speak a word to understand and use the gesture hand gesture and ask you again. An effort to understand is necessary. Power to hear is not enough to us. I think that you must not give it up immediately. A communication skill is not only to talk. I say the technique of associating with person. I communicated with many people by this class. I had a lot of fun! Thank you.

\section{Reflection $7^{\star}$}

Other two classes' level and motivation to learn was low and I was at a loss. For example, during the teacher's explanation or during the activity, they were chatting the entire time. My partner wasn't able to recall any of the vocabulary, so I couldn't improve myself. I think this joint style should not be selected and if it were to be done, it should only be with Education department students.

\section{Reflection 8*}

I didn't know what to ask when I didn't understand the speaker, but now I know how to ask questions, and I can continue conversations. I think it is necessary to communicate in English. Even at my parttime job, there are many foreign customers coming so I think Japan is becoming more globalized. It was a good opportunity to improve my English skills.

\section{Reflection 9*}

Until high school, most classes were lecture style, and we didn't even do listening practice. ELF classes are new because we focus on more practical things like communication and presentations. By thinking about the strategies to make myself understood, I have started using more gestures than before I took this class.

\section{Reflection 10*}

It was fun. I couldn't continue conversation before, but after I learned these communication strategies, I felt that I could continue talking. Compared to before the lessons, I feel the communication is going well.

\section{Reflection 11}

Communicative competence improved by performing three times of joint classes. Especially, I feel talking skills. Because, I learn about pronunciation and body language. Furthermore, I takes with a stranger. It was nervous. But it was good experience. The 3 joint lessons are very difficult. But I could know my bad point and my communication skills improved. The 3 joint lessons and ELF class was good for me. I think that I want to make use of this learning in the future.

\section{Reflection 12}

I think that my communication skills have improved thanks to the 3 joint lessons. My English is poor, but I was able to know that I could convey that I wanted to talk by various means. In addition, I was able to be conscious of the pronunciation, too. In particular, body language is the usefulest for me. Because, I convey that I want to say without a sentence. I really want to use body language. Because, ELF students were able to know English except the sentence.

Note. Reflections 1, 2, 7, 8, 9, 10 were written by the students in Japanese and translated by one of the authors, a native Japanese speaker, into English and then checked by another native Japanese speaker. 